\title{
ORIGINAL ARTICLE \\ Single Burr Hole Craniostomy for Evacuation of Chronic Subdural Hematoma
}

\author{
Sami Hassanain Mohamed Salem ${ }^{1}$, Hosni Hasan Abdalla Salama ${ }^{1}$, Ashraf Mohamed \\ Mohamed Algallad ${ }^{1}$, Esam Mussa Alnajar ${ }^{2} *$
}

\author{
${ }^{1}$ Neurosurgery departments, Faculty of Medicine, Zagazig university, Zagazig, Egypt. \\ ${ }^{2}$ Neurosurgery department, Benghazi university, Benghazi, Libya.
}

\section{*Corresponding author: \\ Esam F Mussa Alnajar neurosurgery Benghazi university, Benghazi, Libya esammussa85@gmail.com}

$\begin{array}{ll}\text { Submit Date } & \text { 3-4-2019 } \\ \text { Revise Date } & \text { 8-6-2019 } \\ \text { Accept Date } & \text { 13-6-2019 }\end{array}$

Background: Chronic subdural hematoma (CSDH) is a rising neurosurgical entity especially in elderly people. Objectives: To assess the value of using single burr hole craniostomy in the evacuation of chronic subdural hematoma according to the clinical picture. Methods: Prospective single-center study included 24 patients having CSDH. The postoperative outcome was assessed immediately after surgery in the ward, and then two weeks in the outpatient clinic for follow up. All patients underwent single burr hole craniostomy during the period between April 2018 to September 2018. Results: Our results were close to other reports. Epidemiologically, female to male ratio of 1:2.4 the main symptom was a headache (62.5. Disturbed conscious level (66.67\%) was the main presenting sign. trauma was a commonest risk factor $(45.8 \%)$ followed by hypertension and diabetes mellitus (20.83\%) each. All patients had GCS above 11 , over $83 \%$ of patients had a significant midline shift of above $5 \mathrm{~mm}$, which is significant for the complications and hospital stay. Most of the participants were Markwalder grade two (45.8\%) followed by grade one $(37.5 \%)$ before the operation, in comparison with Markwalder grade zero (79.2\%) followed by grade one $(12.5 \%)$ after the operation. High significant results were found between and the GOS and hospital stay, and between the GOS and GCS.

Conclusion: single burr-hole craniostomy maneuver is comprehensive and safe management; having a short operating time with low recurrence and mortality rate.

Key-words: Burr hole craniostomy; Glasgow coma scale; chronic subdural hematoma.

\section{INTRODUCTION}

SDH is a standout amongst the most widely recognized sorts of intracranial hematomas particularly in older individuals who supported minor head injury [1]. Balser and associates ${ }^{1}$ evaluated the occurrence of 39 for every 100,000 from admissions to the Veterans Affairs emergency clinic framework in the territory of New York somewhere in the range of 2000 and 2012.

$\mathrm{CSDH}$ is dark adjusted liquid blood, matured over 3 weeks [2] and shows up as a crescentic subdural gathering, iso, mix or hypodense in CT check and essentially hyperintense in MRI [3,4].

Risk factors incorporate head injury, which 
is generally minor, propelled age because of cerebrum decay that prompts extending of subdural space and extending the connecting delicate subdural veins, the typical antiplatelet organization, and progressively propensity to fall [5]. Potential factors that extend $\mathrm{CSDH}$ after some time are an osmotic inclination of hemolytic items, low oncotic weight inside the hematoma container, rehashed smaller scale draining, anticoagulant and profibrinolytic materials, inflammatory and growth factors role [6]. In this way, a wash of subdural blood through irrigation can nullify these elements that incline to recurrence ${ }^{2}$.

Markwalder et al., (1981) displayed clinical picture classification of CSDH into 5 grades ranging from Grade zero: (asymptomatic) to a Grade four: (coma, flexes/extends to pain) [7].

Computerized tomography (CT) check discoveries incorporate brain decay, midline shift, crescent shape subdural hematoma of various densities and area generally in the frontoparietal or fronto-parieto-occipital convexity. Most CSDHs are hypodense in CT yet perhaps isodense or of mix densities because of membranous layers of blood. Isodense CSDHs are better assessed by MRI, to delineate more detailed structure of the hematoma like septae, or membranes with hyperintensity in both $\mathrm{T} 1$ and $\mathrm{T} 2$ sequences [4].

Surgical management has been commonly acknowledged as the best administration strategy for CSDH. Many surgical techniques ranging from simply twist drill tapping and aspiration to increasingly intrusive procedures including single burrhole drainage, augmented burr-hole (small craniectomy), numerous burr-holes drainages, and complex craniotomy (weather with or without membranectomy) (with or without subgaleal drainage or subdural closed drainage system) was utilized. There is a relationship between the rate of recurrence and the surgical technique utilized [9].

\section{SUBJECTS AND METHODS}

\section{Site of study:}

All patients underwent single burr hole craniostomy in the department of neurosurgery, Zagazig university hospital, during the period between April 2018 to September 2018.

Sample size:

This prospective single-center study included 24 patients had symptomatic CSDH.

\section{Inclusion criteria}

A patient who has a symptomatic CSDH. Patients or first-degree relative consent to enter the study. Unilocular CSDH.

\section{Exclusion criteria}

A patient who has an acute subdural hematoma or Septated CSDH.

\section{Methods:}

Preoperative assessment and preparation

All patients were subjected to:

Detailed history intake,

Physical examination including the application of Markwalder score on admission and before patients' discharge to home.

Laboratory evaluation,

Radiological evaluation by applying Nonenhanced CT to obtain: The degree of midline shift, the laterality and the density of the contents of the CSDH.

Written informed consent was obtained from all participants and the study was approved by the research ethical committee of the Faculty of Medicine, Zagazig University. The work has been carried out in accordance with The Code of Ethics of the World Medical Association (Declaration of Helsinki) for studies involving humans.

\section{Operative assessment}

\section{Anesthesia}

Of these patients, 5 underwent surgery under local anesthesia and 19 were evacuated under general anesthesia. 


\section{Surgical procedure}

All patients underwent surgery in the supine position. A single burr hole was drilled with a Hudson brace and placed at the posterior frontal region. Dura was opened to decompress the hematoma slowly.

It was very important to inform the anesthetist prior to performing the drainage that the blood pressure should be closely monitored and maintained at normal levels while gently infusing normal saline during surgery. The technique involved rapid syringing of saline in the form of a jet circumferentially through the burr hole under controlled pressure. On completion of the irrigation, the head was slowly filled with saline to eliminate air to a maximum possible extent before skin closure.

\section{Postoperative assessment}

Postoperatively, the patient was adequately hydrated and restricted to bed rest in the supine position with head resting on one pillow.

The drain was removed after 48_72 hours. Use of anticonvulsants was restricted only to those with a previous seizure history. Steroid not used in any patient.

The outcome of patients was done according to GCS, GOS and Markwalder grade at discharge.

All patients were followed after 2 weeks of the procedure.

Data has been analyzed and presented by using the Statistical Package for Social Scientists (SPSS USA Inc) Version 25.0.

\section{RESULTS}

Our results were close to other reports. Epidemiologically, female to male ratio of $1: 2.4$. The main symptom was a headache $(62.5 \%)$, followed by a positive history of vomiting $(20.8 \%)$. Disturbed conscious level $(66.67 \%)$ was the main presenting sign followed by limb weakness $(25 \%)$. trauma was the commonest risk factor $(45.8 \%)$ followed by hypertension and diabetes mellitus (20.83\%) each. All patients had GCS above 11 , over $83 \%$ of patients had a significant midline shift of above $5 \mathrm{~mm}$, which is significant for the complications and hospital stay. Most of the participants were Markwalder grade two (45.8\%) followed by grade one $(37.5 \%)$ before the operation, in comparison with Markwalder grade zero $(79.2 \%)$ followed by grade one $(12.5 \%)$ after the operation. High significant results were found between and the GOS and hospital stay, and between the GOS and GCS.

Table 1: Demographic data of the studied patients.

\begin{tabular}{|c|c|c|c|}
\hline \multicolumn{2}{|c|}{ Demographic data } & \multicolumn{2}{|c|}{$\begin{array}{l}\text { The studied patients } \\
\qquad(\mathrm{N}=24)\end{array}$} \\
\hline \multicolumn{2}{|c|}{$\begin{array}{c}\text { Age (years) } \\
\text { Mean } \pm \text { SD } \\
\text { Median (Range) }\end{array}$} & \multicolumn{2}{|c|}{$\begin{array}{c}60.01 \pm 8.817 \\
59(38-76)\end{array}$} \\
\hline \multirow[t]{2}{*}{ Sex } & Male & 17 & $70.8 \%$ \\
\hline & Female & 7 & $29.2 \%$ \\
\hline
\end{tabular}


Table 2: Patients' presentation of the studied group

\begin{tabular}{|c|c|c|}
\hline \multirow[t]{2}{*}{ Patients' presentation } & \multicolumn{2}{|c|}{$\begin{array}{l}\text { The studied patients } \\
\qquad(\mathrm{N}=24)\end{array}$} \\
\hline & No. & $\%$ \\
\hline Headache & 15 & $62.5 \%$ \\
\hline Nausea/vomiting & 1 & $4.17 \%$ \\
\hline Fits & 0 & $0 \%$ \\
\hline Decreased level of consciousness & 16 & $66.67 \%$ \\
\hline Blurred vision & 1 & $4.17 \%$ \\
\hline Limb weakness & 4 & $25 \%$ \\
\hline Limb paralysis & 4 & $12.5 \%$ \\
\hline Dysarthria & 2 & $8.3 \%$ \\
\hline Traumatic brain injury & 0 & $0 \%$ \\
\hline Gait disturbance & 3 & $12.5 \%$ \\
\hline
\end{tabular}

Table 3: GCS of presented participants

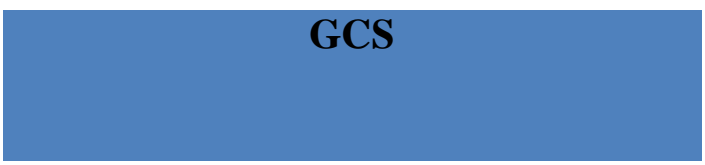

Mean \pm SD

Median (Range)

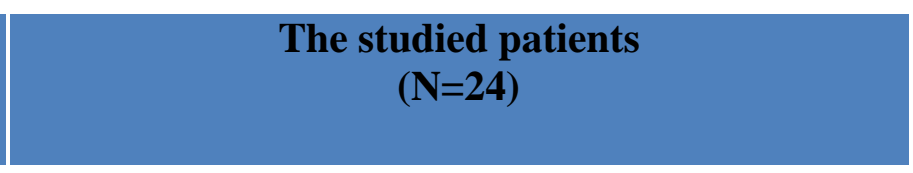

$13.83 \pm 1.09$

$14(12-15)$ 
Table 4: CT characteristics of cSDH in correlation with Markwalder grades

\begin{tabular}{|c|c|c|c|c|c|c|c|c|c|c|}
\hline \multicolumn{2}{|c|}{ CT characteristics of $\mathbf{c S D H}$} & \multicolumn{8}{|c|}{ Markwalder grades } & \multirow{3}{*}{ 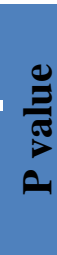 } \\
\hline & & \multicolumn{2}{|c|}{0} & \multicolumn{2}{|c|}{1} & \multicolumn{2}{|c|}{2} & \multirow{2}{*}{$\begin{array}{c}3 \\
\mathrm{~N} / \%\end{array}$} & \multirow{2}{*}{$\begin{array}{c}4 \\
\mathrm{~N} / \%\end{array}$} & \\
\hline & & $\mathrm{N}$ & $\%$ & $\mathrm{~N}$ & $\%$ & $\mathrm{~N}$ & $\%$ & & & \\
\hline \multirow{4}{*}{ 离 } & Isodense & $\nabla$ & $\stackrel{\vec{\lambda}}{ }$ & N & i̊ & 0 & $\stackrel{0}{0}$ & 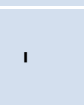 & ' & \\
\hline & Mixed density & $\nabla$ & 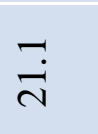 & 一 & $m$ & 0 & $\stackrel{\circ}{0}$ & & ' & * \\
\hline & Hypodense & $\underline{0}$ & 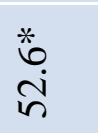 & 0 & $\stackrel{\circ}{0}$ & 0 & $\stackrel{0}{0}$ & ' & ' & $\stackrel{\circ}{\circ}$ \\
\hline & Hyperdense & 一 & $\stackrel{m}{n}$ & 0 & $\stackrel{\circ}{\circ}$ & $\mathrm{N}$ & $\stackrel{0}{8}$ & ' & ' & \\
\hline \multirow{3}{*}{$\stackrel{2}{\circ}$} & Left & r & $\begin{array}{l}\infty \\
0 \\
\infty\end{array}$ & $m$ & $\stackrel{0}{8}$ & $\mathrm{~N}$ & $\stackrel{0}{8}$ & ' & ' & \\
\hline & Right & $\infty$ & 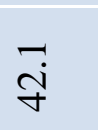 & 0 & $\stackrel{0}{0}$ & 0 & $\stackrel{0}{0}$ & ' & ' & $\stackrel{ }{0}$ \\
\hline & Bilateral & $\nabla$ & $\stackrel{\sqsupset}{\dot{\lambda}}$ & 0 & $\stackrel{\circ}{0}$ & 0 & $\stackrel{0}{0}$ & ' & 1 & \\
\hline \multirow{4}{*}{ 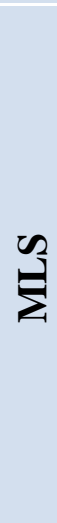 } & $<5$ & $\nabla$ & 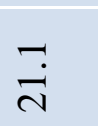 & 0 & $\stackrel{\circ}{0}$ & 0 & $\stackrel{0}{0}$ & ' & ' & \multirow{4}{*}{$\stackrel{*}{\stackrel{*}{8}}$} \\
\hline & $5-10$ & $m$ & $\stackrel{*}{\stackrel{*}{*}}$ & 0 & $\stackrel{0}{0}$ & 0 & $\stackrel{\circ}{0}$ & ' & ' & \\
\hline & $10-15$ & N & $\stackrel{n}{\varrho}$ & $N$ & ) & $N$ & $\stackrel{0}{8}$ & ' & ' & \\
\hline & $>15$ & 0 & $\stackrel{0}{0}$ & 0 & $\stackrel{0}{0}$ & - & $\stackrel{m}{m}$ & ' & ' & \\
\hline
\end{tabular}


Table 5: postoperative complications

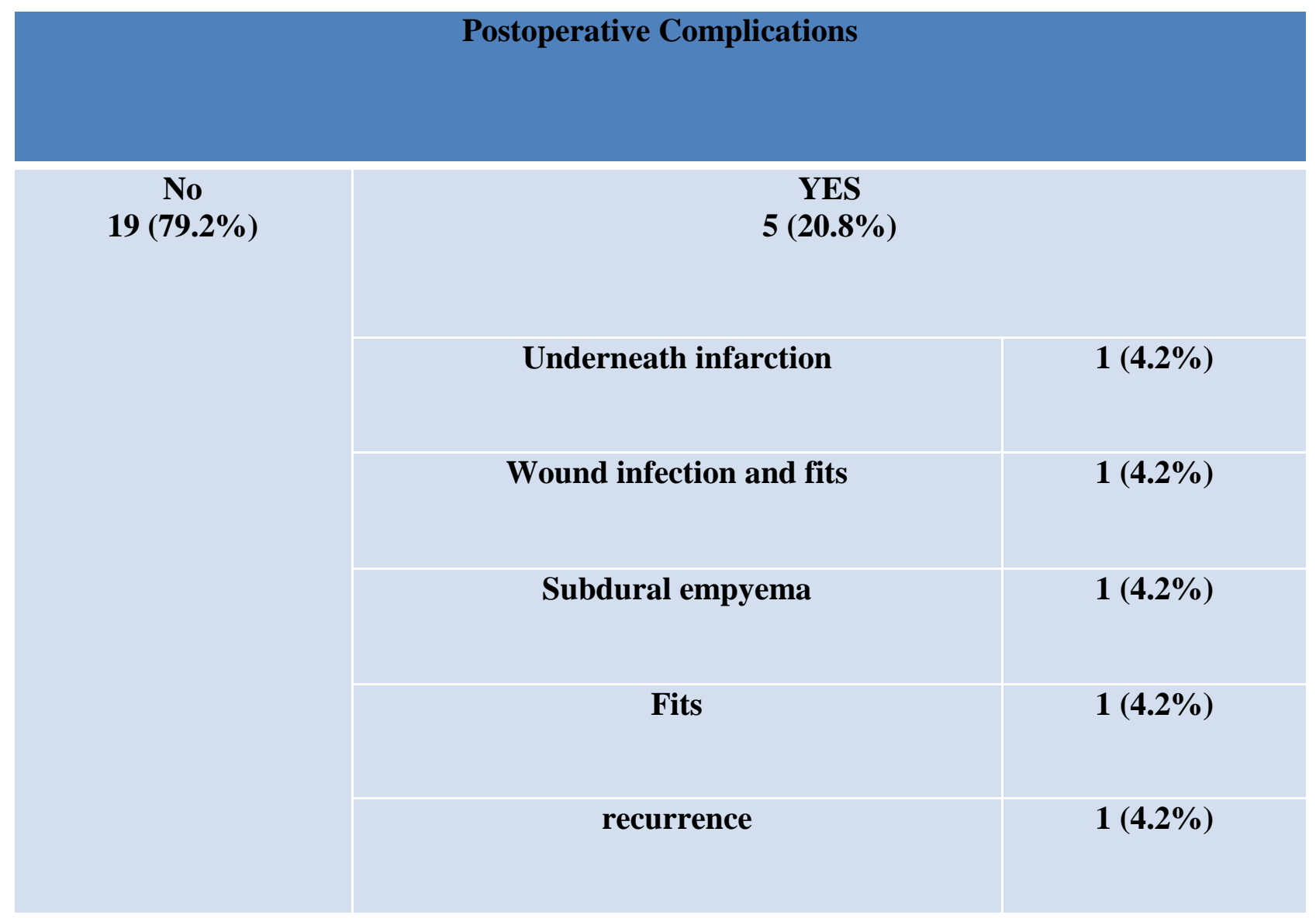


Table 6: changes in MarkWalder scores pre and postoperatively.

\begin{tabular}{|c|c|c|c|c|}
\hline \multirow[t]{3}{*}{ Grades } & \multicolumn{4}{|c|}{$\begin{array}{l}\text { The studied patients } \\
\qquad(N=24)\end{array}$} \\
\hline & \multicolumn{2}{|c|}{ Before } & \multicolumn{2}{|c|}{ After } \\
\hline & No. & $\%$ & No. & $\%$ \\
\hline 0 & 0 & $0.0 \%$ & 19 & $79.2 \%$ \\
\hline 1 & 9 & $37.5 \%$ & 3 & $12.5 \%$ \\
\hline 2 & 11 & $45.8 \%$ & 2 & $8.3 \%$ \\
\hline 3 & 4 & $16.7 \%$ & 0 & $0.0 \%$ \\
\hline 4 & 0 & $0.0 \%$ & 0 & $0.0 \%$ \\
\hline Total & 24 & $100.0 \%$ & 24 & $100.0 \%$ \\
\hline
\end{tabular}

Table 7: GCS in correlation with hospital stay and GOS

\begin{tabular}{|c|c|c|}
\hline GCS and hospital stay & $\mathbf{r}$ & $\mathbf{P}$ \\
\hline GCS and GOS & -0.69 & $<0.001 * *$ \\
\hline
\end{tabular}

\section{DISCUSSION}

Out of 24 cases in our study, the participants' mean age (59 years old) which was lesser than the vast majority of the series audited; 64 for Rohde et al. ${ }^{3}, 65$ years in the series of Krupp and Jans ${ }^{4}$, and 67 in other studies. ${ }^{5,6}$.

Epidemiologically, our outcomes were not the same as different reports. Male to female proportion of 2.4:1 in our CSDH patients is close to other reported, such as 1.7:1 ${ }^{78}$, 1.8:1 ${ }^{9}$, and 2.5:1 ${ }^{10}$. This could be attributed to the majority of the participants being male and more likely to suffer trauma. It may also be attributed to the fact that males are the main workers in the community.
In our study, some of the participants showed evidence of more than one group of symptoms but the majority signaled with only one element. The main symptoms were a headache $(62.5 \%)$ followed by a positive history of nausea and vomiting with $(4.17 \%)$ although CSDH patients with altered consciousness fail to give details of their complaints.

Disturbing level of consciousness was the main presenting sign $(66.67 \%)$ and followed by lateralizing signs (paresis) $(25.0 \%)$. Gait disturbance and limb plegia accounted $(12.5 \%)$ of the presenting complaints. These findings are consistent with the data published by Santarius et $\mathrm{al}^{11}$ and Gelabert- 
Gonzáles et al. ${ }^{7}$ The least presenting complaints were slurred speech $(8.3 \%)$ and blurred vision (4.17\%). None of the participants was having fits at the time of presentation which is lesser than that of Alexander et al. ${ }^{12}$

Trauma, which was the most important risk factor in our study (45.8\%) and it, was mostly minor and remote. The mean duration to the onset of symptoms is one month (range was 2 weeks to 2 months). The major causes were falls and a road traffic accident. Compared to what is in literature; Lee et al(1998) noted in his series that acute subdural hematoma as a result of major head trauma turned to CSDH in only $3 \%-6 \%$ of cases $^{13}$; however, minor head insult has been confirmed by different authors $^{14,15}$ to be a major predisposing factor. Stroobandt, in his study of 100 patients, found it be as high as $80 \%$, compared to taking aspirin (16\%), coagulopathy $(6 \%)$ and ethylism $(11 \%) .{ }^{16}$ Although the history of use of anticoagulant was at $12.5 \%$ in our study, most of the participants had acceptable coagulation profile with INR <1.8. Coagulopathy was found in three patients $(12.5 \%)$ however, all of them had Warfarin Consumption. These findings compared favorably with literature finding, where the incidence of coagulopathy ranges from $10 \%$ to as high as $42 \%$ as found by different authors Grisoli et al (1985)10\%. ${ }^{15,17}$, Hardes et al(1981)18\% ${ }^{18}$, Reymond et al (1992)26\% ${ }^{15}$. In the case of $\mathrm{DM}$ as a risk factor for developing $\mathrm{cSDH}$, there might be a few explanations behind the expanded hazard of SDH in DM patients. Schwartz et al. ${ }^{19}$ have discovered that diabetic females are related with an increased hazard of fall in a prospective cohort study. They additionally discovered that poor balance, a background of CAD, arthritis and peripheral neuropathy might represent for some of the increased danger of fall related with non-insulin treated diabetes. ${ }^{19}$ A recent report by Roman de Mettelinge et al. ${ }^{20}$ pursued elderly individuals (104 with diabetes and 95 healthy controls) for a year and revealed that diabetic patients had an odd ratio of 2.03 (95\% CI 0.49-099) for fall, contrasted with controls. 21,22 Cognitive abnormalities induced by high or low blood glucose levels and diabetes complications such as retinopathy and peripheral neuropathy contributes to the increased risk of motor vehicle accidents in diabetic individuals. ${ }^{23}$

In our study, of all the risk factors that have been associated with $\mathrm{CSDH}$ and discussed earlier, trauma was commonest with $(45.8 \%)$ giving a history of head trauma within 2 months before diagnosis. followed by hypertension and diabetes mellitus $(20.83 \%)$. The use of anticoagulation (Marivan) and patients who had the chronic liver disease were $(12.5 \%)$ of the studied group. There were $(25.0 \%)$ of the studied patients having more than one risk factors. Glasgow Coma Scale is a measurement of the conscious level, which is itself corresponded with the seriousness of head injury in acute head injuries. In any case, the conscious level in CSDH as a chronic state chiefly relies upon non-traumatic components, that is, those not identified with the head injury itself. therefore It is judicious to consider GCS as a marker of the conscious level as opposed to the seriousness of head injury in $\mathrm{CSDH}^{24}$

In the assessment of Glasgow coma scale in the present study on admission, it was found that majority of the patients had Glasgow coma scale of $15(37.5 \%)$ or $14(33.33 \%)$ followed by $12(16.67 \%)$ and the least presented Glasgow score was 13 (12.5\%).

CT or MRI remains an investigation of choice alongside full laboratory investigations to preclude comorbid conditions. CT is sufficient and adequate for diagnosis and it can present as hypo, iso or hyperdense abnormality relying upon the 
chronicity of the subdural blood. nevertheless, the multiple traumatic head injuries can lead to mixed findings.

The nonhomogeneity of cSDH occurs as part of the intermittent cyclic process of hemorrhage originating from external membrane capillaries favored by FDPs or as a consequence of new trauma. ${ }^{25}$ This was confirmed by Stansic et al(2005) in relation to postoperative recurrence where he subclassified the acute on chronic into separated density subtype $43.8 \%$, laminar density type $(26.7 \%)$ making up a total of $70.5 \%$ compared to trabecular density type (CSDH with membranes) (18.8\%) subacute type $(11.8 \%)$.

In our study, we excluded the septated subdural hematoma and the common radiological pattern was a chronic hypodense subdural hematoma (41.7\%) followed by a subacute isodense subdural hematoma $(25.0 \%)$ and There was no statistical significance between patients' presentations and the degree of subdural hematoma density. Mixed density on CT scans revealed $(20.8 \%)$ of the study group.

We found also that over $83 \%$ of the participants had a midline shift above $5 \mathrm{~mm}$ however, $4.2 \%$ of them were presented with a midline shift of over $15 \mathrm{~mm}$. also, there was an association between gait disturbance and a midline shift more than $15 \mathrm{~mm}$ $(\mathrm{p}=0,03)$. There was, however, no statistical significance between other patients' presentations and the midline shift.

We found in this study that half of the participants were having a left-sided subdural hematoma, while the third of the studied patients had a right subdural hematoma and about $16.7 \%$ had a bilateral subdural hematoma. However, there was no statistical significance between patients' presentations and the site of a hematoma. Moreover, there was a significant $(\mathrm{p}=0.01)$ correlation between the site of subdural hematoma in the study group and the level of consciousness. There was also a significance between the GCS and the density of the subdural hematoma ( $p$-value 0.005). Moreover, a highly significant correlation was seen between the midline shift and GCS with a p-value of less than 0.001 .

Treatment of CSDH ought to be successful, safe, in fact simple, and cost-productive. McKissock et al. ${ }^{26}$ were pioneers in the management of CSDH by simple burr-hole drainage with a significant decrease in mortality rate. In 1964, Svien and Gelety ${ }^{27}$ detailed that burr-hole drainage was better than craniotomy with membranectomy. Burr-hole treated patients had a lower reoperation rate and better results in their series.

Inspite of the fact that burr hole drainage remains the commonest type of treatment of CSDH, our literature inquiry couldn't yield an article that studied and compared the results of single versus double burr hole drainage of $\mathrm{CSDH}^{28}$ However, two-burr holes drainage was considered to yield a superior result, particularly with respect to subdural collection recurrence. In the largest meta-analysis of 34,829 patients, it was appeared whatever the essential technique the utilization of drains resulted in lesser recurrence and craniotomy was better for recurrent cases. $^{29}$ Nevertheless, in the occurrence of insufficient drainage intraoperatively and postoperatively ${ }^{30}$, air accumulation in the hematoma cavity ${ }^{31}$ are thought to expand the hazard of recurrence.

On postoperative results, we had a (79.2\%) favorable outcome according to one modality of intervention (single Burr hole craniostomy with irrigation). This contrasts positively and the one in literature indicated to William et al ${ }^{32}$, where $16 \%$ of those with burrhole without drain got worse postoperatively and $11 \%$ needed evacuation contrasted to $7 \%$ with drains in situ who deteriorated postoperatively and needed re- 
intervention and $64 \%$ with Twist drill craniostomy without suction who needed reoperation.

For postoperative Complication in the present study, five $(20.8 \%)$ patients were having a postoperative complication. In which one patient $(4.2 \%)$ had a recurrence the same patient had initial INR of 3.4 and was on warfarin, one patient $(4.2 \%)$ had subdural empyema, one patient $(4.2 \%)$ had fit, one patient $(4.2 \%)$ had underneath infarction, and the last patient $(4.2 \%)$ had wound infection and fit at the same period.

By considering the length of hospital stay in the present study with an average of 4 days and a positive relationship (p-value; 0.04) between the midline shift in CT scan results and hospital stayed days. This constitutes superior outcome in comparing to literature like in Taussky $\mathrm{P}^{2}$ where he compared two $\mathrm{BHC}$ and one burrhole, where the average stay was 9 days for $2 \mathrm{BHC}$ and 11 days for one BHC.

However, highly significant results were found between and the GOS and hospital stay, and between the GOS and GCS.

\section{CONCLUSION}

The present agreement is that symptomatic CSDH is best treated surgically, and in spite of the fact that $\mathrm{BHC}$ is commonly acknowledged as the principal line for surgical treatment around the world, further work should be done to refine signs for the distinctive surgical maneuvers. What's more, there is a need to characterize the value of adjuvant treatments like steroids.

The single burr-hole craniostomy maneuver is a sufficient and safe method of surgical treatment; having a short operating time, minimum recurrence rate and less mortality rate. Given that the burden of $\mathrm{CSDH}$ is set to ascend in the coming years, there is a need to enhance outcomes for this popular neurosurgical condition.

\section{ACKNOWLEDGMENT}

The authors are grateful for the patients without whom this study would not have been done.

\section{Declaration of interest}

The authors report no conflicts of interest. The authors alone are responsible for the content and writing of the paper.

Funding information: None declared

\section{REFERENCES}

1. Balser D, Farooq S, Mehmood T, Reyes M, Samadani U. Actual and projected incidence rates for chronic subdural hematomas in United States Veterans Administration and civilian populations. $J$ Neurosurg. 2015;123(5):1209-1215. doi:10.3171/2014.9.JNS141550

2. Coulter IC, Kolias AG, Marcus HJ, Ahmed AI, Alli S, Al-mahfoudh R, Borg A. Proposal for a prospective multi-centre audit of chronic subdural haematoma management in the United Kingdom and Ireland. $\mathrm{Br} J$ Neurosurg. 2014;28(2):199-203.

3. Rohde V, Graf G, Hassler W. Complications of burr-hole craniostomy and closed-system drainage for chronic subdural hematomas: a retrospective analysis of 376 patients. Neurosurg Rev. 2002;25(1-2):89-94.

4. Krupp WF, Jans PJ. Treatment of chronic subdural haematoma with burr-hole craniostomy and closed drainage. $\mathrm{Br} \quad \mathrm{J}$ Neurosurg. 1995;9(5):619-628.

5. Nakaguchi $H$, Tanishima $T$, Yoshimasu N. Factors in the natural history of chronic subdural hematomas that influence their postoperative recurrence. $J$ Neurosurg. 2001;95(2):256-262.

6. Reinges MHT, Hasselberg I, Rohde V, Küker W, Gilsbach JM. Prospective analysis of bedside percutaneous subdural tapping for the treatment of chronic subdural haematoma in adults. I Neurol Neurosurg Psychiatry. 2000;69(1):40-47.

7. Gelabert-González M, Iglesias-Pais M, Garcl'lia-Allut A, Martl'linez-Rumbo R. Chronic subdural haematoma: surgical treatment and outcome in 1000 cases. Clin Neurol Neurosurg. 2005;107(3):223-229.

8. Miranda LB, Braxton E, Hobbs J, Quigley MR. Chronic subdural hematoma in the elderly: not a benign disease. J Neurosurg. 
2011;114(1):72-76.

9. Baechli H, Nordmann A, Bucher HC, Gratzl O. Demographics and prevalent risk factors of chronic subdural haematoma: results of a large single-center cohort study. Neurosurg Rev. 2004;27(4):263-266.

10. MORI K, MAEDA M. Surgical treatment of chronic subdural hematoma in 500 consecutive cases: clinical characteristics, surgical outcome, complications, and recurrence rate. Neurol Med Chir (Tokyo). 2001;41(8):371-381.

11. Santarius T, Kirkpatrick PJ, Kolias AG, Hutchinson PJ. Working toward rational and evidence-based treatment of chronic subdural hematoma. Clin Neurosurg. 2010;57:112122.

12. Hammer A, Tregubow A, Kerry G, Schrey M, Hammer C, Steiner H-H. Predictors for Recurrence of Chronic Subdural Hematoma. Turk Neurosurg. 2016:17316-17347.

13. WK BAE JW DOH HGBAEIGYUNLEEKS. Origin of chronic subdural haematoma and relation to traumatic subdural lesions. Brain Inj. 1998;12(11):901-910.

14. Hamilton MG, Frizzell JB, Tranmer BI. Chronic subdural hematoma: the role for craniotomy reevaluated. Neurosurgery. 1993;33(1):67-72.

15. wasike drgb. chronic subdural haematoma in kenyan adults at the kenyatta national hospital: clinical patterns, risk factors and immediate post operative outcome. 2012.

16. Stroobandt G, Fransen P, Thauvoy C, Menard E. Pathogenetic factors in chronic subdural haematoma and causes of recurrence after drainage. Acta Neurochir (Wien). 1995;137(1-2):6-14.

17. Weir B, Gordon P. Factors affecting coagulation: fibrinolysis in chronic subdural fluid collections. $J$ Neurosurg. 1983;58(2):242-245.

18. Harders A, Weigel K, Gilsbach J, Eggert H-R. Follow-up and results of external drainage therapy of chronic subdural hematomas. In: Brain Abscess and Meningitis. Springer; 1981:388-390.

19. Schwartz A V, Hillier TA, Sellmeyer
DE, Resnick HE, Gregg E,Ensrud KE, Schreiner P. Older women with diabetes have a higher risk of falls: a prospective study. Diabetes Care. 2002;25(10):1749-1754.

Schwartz, A.V., Hillier, T.A., Sellmeyer, D.E., Resnick, H.E., Gregg, E., Ensrud, K.E., Schreiner, $\mathrm{P}$

20. de Mettelinge TR, Cambier D, Calders $\mathrm{P}$, Van Den Noortgate N, Delbaere K. Understanding the relationship between type 2 diabetes mellitus and falls in older adults: a prospective cohort study. PLoS One. 2013;8(6):e67055.

21. Schwartz A V, Vittinghoff E, Sellmeyer DE, Feingold KR, De Rekeneire N, Strotmeyer ES, et al. Diabetes-related complications, glycemic control, and falls in older adults. Diabetes Care. 2008;31(3):391396.

23. Stork ADM, Van Haeften TW, Veneman TF. Diabetes and driving: desired data, research methods and their pitfalls, current knowledge, and future research. Diabetes Care. 2006;29(8):1942-1949.

24. Abouzari M, Rashidi A, Rezaii J, Esfandiari K, Asadollahi M, Aleali $\mathrm{H}$ and Abdollahzadeh. The role of postoperative patient posture in the recurrence of traumatic chronic subdural hematoma after burr-hole surgery. Neurosurgery. 2007;61(4):794-797.

25. Saito K, Ito H, Hasegawa T, Yamamoto S. Plasmin-\$ $\alpha$ 2-plasmin inhibitor complex and $\$ \alpha \$ 2$ 2-plasmin inhibitor in chronic subdural hematoma. $J$ Neurosurg. 1989;70(1):68-72.

26. Mckissock W, Richardson A, Bloom W. Subdural haematoma: a review of 389 cases. Lancet. 1960;275(7139):1365-1369.

27. Svien HJ, Gelety JE. On the surgical management of encapsulated subdural hematoma: A comparison of the results of membranectomy and simple evacuation. $J$ Neurosurg. 1964;21(3):172-177.

28. Kansal R, Nadkarni T, Goel A. Single versus double burr hole drainage of chronic subdural hematomas. A study of 267 cases. $J$ Clin Neurosci. 2010;17(4):428-429.

29. Almenawer SA, Farrokhyar F, Hong C, Alhazzani W, Manoranjan B, Yarascavitch B, Arjmand. Chronic subdural hematoma management: a systematic review and meta- 
analysis of 34829 patients. 2014.

30. Robinson RG. Chronic subdural hematoma: surgical management in 133 patients. J Neurosurg. 1984;61(2):263-268.

31. Okada Y, Akai T, Okamoto K, Iida T, Takata H, lizuka H. A comparative study of the treatment of chronic subdural hematoma burr hole drainage versus burr hole irrigation. Surg Neurol. 2002;57(6):405409.

32. Williams GR, Baskaya MK, Menendez J, Polin R, Willis B, Nanda A. Burr-hole versus twist-drill drainage for theevacuation of chronic subdural haematoma: a comparison of clinical results. $J$ Clin Neurosci. 2001;8(6):551-554.

To Cite This Article: Salem SH, Salama HH ,Algallad AM Alnajar EM,. Single Burr Hole Craniostomy for

Evacuation of Chronic Subdural Hematoma. Zumj 2020; 27(2)221-232: doi
10.21608/zumj.2019.11139.1153 